\title{
Bautista Serra, un agente genovés en la Corte de Felipe III: Lo parti- cular y lo público en la negociación política*
}

\author{
Yasmina Ben Yessef Garfia \\ Universidad Pablo de Olavide, Sevilla
}

RESUMEN: El protagonismo de particulares y de familias genovesas en el equilibrio de poderes europeo del Antiguo Régimen es fundamental para la comprensión de los procesos de toma de decisiones y de muchas de las estrategias que contribuyeron al manejo de las situaciones de crisis por parte de la Monarquía Hispánica. Así lo pone de manifiesto la actuación de Bautista Serra, agente en Madrid por parte de la República de Génova entre 1614 y 1618. Las instrucciones dadas por la República a Serra, encaminadas al mantenimiento del estatus de Génova y a la preservación de los privilegios de la comunidad genovesa que operaba en los territorios del monarca católico, no excluían la puesta en práctica por parte del agente de modos de negociación alternativos que garantizaran no sólo el éxito de la misión sino también la obtención de beneficios particulares y para otros genoveses. Se trataba de otras vías para la obtención del consenso que complementaban las vías oficiales y que dependian enormemente de la inserción de la familia en las redes de elites internacionales y en los circuitos de patronazgo regio.

\section{Palabras Clave: Génova; Monarquía Hispánica; Particulares; Ne- gociación; Redes transnacionales; Familias; Serra.}

Bautista Serra, a Genovese Agent in the Court of Phillip II of Spain: The particular and the private in the political negotiation

ABSTRACT: The prominent role played by certain Genoese private individuals and families in the European power balance during the Ancient Régime is essential for understanding the decision making processes and the

* Las fuentes precisadas en este artículo proceden de los siguientes archivos: Archivo General de Simancas (AGS) y Archivio di Stato di Genova (ASGe). 
strategies followed by the Spanish monarchy for the management of critical situations. A telling example is that of Bautista Serra, agent of the Genoese Republic in Madrid between 1614 and 1618. Serra's instructions aimed at the preservation of Genoa's status and the perpetuation of the privileges enjoyed by the Genoese in the lands under the Spanish monarch. This, however, did not exclude alternative paths of negotiation not only in order to guarantee the success of his mission, but also to obtain personal gains for him and other Genoese subjects. These were alternative resources in order to get a consensus that complemented the official ones, and that depended on the ability of certain families to enter into international elite networks and to interact with the circles of royal patronage

KEY WORDS: Genoa; Spanish Monarchy; Private Individuals; Negotiation; Transnational Networks; Families; Serra.

\section{GÉNOVA, UNA REPÚBLICA DE PARTICULARES ${ }^{1}$}

Los acontecimientos políticos y económicos que caracterizaron los primeros años del reinado de Felipe III fueron determinantes en lo que se refiere al grado de estabilidad de lo que se ha denominado el «agregado hispanogenovés» ${ }^{2}$. Si bien las relaciones entre la República de Génova y la Monarquía Hispánica se hallaban consolidadas desde que en 1528 se firmara el tratado de condotta entre Andrea Doria y Carlos V, fenómenos como la bancarrota de 1596 y el tratado de paz con Francia de 1598 sacudirían algunas de las bases sobre las que se apoyaba la alianza. Las consecuencias derivadas de semejante contexto político para las relaciones entre la República y la Corona española fueron ya apuntadas en otro trabajo ${ }^{3}$. No obstante, es necesario recordar aquí las repercusiones de los acuerdos hispano-franceses, que condujeron a Francia al hostigamiento del monarca católico en otros ámbitos a través de una política ambigua que aprovechaba las ambiciones de Saboya, insatisfecha aún después de la recuperación del Marquesado de Saluzzo en 1601, y las inquietudes de algunos de los principales enemigos de la Monarquía Hispánica como Venecia o los holandeses.

La seguridad de Génova como aliada de la Corona española se vería comprometida por un contexto de guerras, tales como las sucedidas entre Francia y la Monarquía Hispánica por el control de los pasos suizos o entre Saboya y

1 El presente artículo ha sido realizado en el marco del proyecto de investigación I+D dirigido por Manuel Herrero Sánchez y denominado «El papel de las repúblicas europeas en la conformación del Estado moderno: ¿alternativa modernizadora o motor del sistema? (siglos XVI-XVII)» (HAR2010-19686), financiado con fondos FEDER.

2 HERRERO SÁNCHEZ, 2001: 183-200.

3 Véase el balance sobre la cuestión en BEN YESSEF GARFIA, 2012: 121-144. 
Madrid por el conflicto sucesorio que tuvo lugar en el Ducado de Mantua entre 1613 y 1617 . Una coyuntura que golpeaba directamente al territorio de la República, como lo demostró la ocupación de sus dominios por los ejércitos hispánicos con el fin de conquistar el enclave saboyano de Oneglia en 1615. Quizás resultaron más graves los efectos indirectos derivados de dicha situación que obstaculizaban la circulación del dinero y se sumaban a los problemas económicos por los que atravesaba la Monarquía Hispánica. Del mismo modo, la adquisición de feudos imperiales en Italia con problemas de sucesión por parte de Madrid y a expensas de los intereses de la República, como puso de manifiesto la incorporación formal de Finale en 1602, constituían factores que incidían radicalmente en los intereses de los particulares genoveses.

Uno de los objetivos de este artículo consiste en la revalorización del papel jugado por estos particulares ligures que, movidos por sus propios intereses individuales, familiares o clientelares y no siempre desde una posición oficial, negociaron con el rey o con sus delegados los conflictos puntuales que mantenía la República con el monarca español y, asimismo, garantizaron el funcionamiento del sistema de asientos que aseguraba la llegada de dinerario a las arcas públicas genovesas ${ }^{4}$. Conviene recordar que a pesar de la coincidencia entre los particulares que se beneficiaban de los tratos con la Corona española y los ciudadanos que componían el ceto dirigente genovés, ello no siempre presumía una actuación homogénea de la oligarquía gobernante en momentos de crisis en los que se requería una acción de Estado coordinada. Si bien en situaciones de tensión financiera la unión del patriciado genovés era lo habitual, el poder de los particulares y su capacidad de negociación directa con la monarquía se anteponían, en numerosas ocasiones, a las pretensiones políticas y al discurso de prestigio de la República. Se producía entonces la interferencia de los intereses propios y los de su red con el cumplimiento de la aclamada virtud republicana del bien público y del interés general ${ }^{5}$.

4 Las distintas grafías con las que aparecían escritos los nombres de estos particulares genoveses, según las fuentes consultadas y el idioma de la misma, junto con la recurrente homonimia en el seno de las familias podían dificultar el seguimiento y la comprensión de los argumentos aquí expuestos. Por ello, anunciamos que, con el fin de facilitar la identificación de los personajes que se mencionan en este artículo, se ha optado por la traducción de sus nombres al castellano actual.

5 Los momentos de crisis financiera de la Corona española como el que condujo a la bancarrota de 1607 suponían una movilización generalizada del «lobby» genovés (no sólo cortesano) que, haciendo uso de sus redes de contactos y correspondientes, conseguía las más de las veces emitir una respuesta conjunta a los ministros españoles que redundaba positivamente en el grupo de banqueros que, en ese momento, dominaba los principales servicios al rey católico. Sin embargo, en lo referido a la familia genovesa de los Serra de la que nos ocupamos en la actualidad, sobresalió el comportamiento insolidario de Bautista Serra en la negociación que siguió a la declaración de suspensión de pagos por parte del monarca católico en 1597. En CANOSA, 2000: 209. Para Podestà, S. Musella y F. Augurio, este Bautista Serra 
Mayores conflictos se producían cuando se trataba de cuestiones más políticas que ponían en juego el estatus internacional de la República. Así, en las primeras décadas del siglo XVII, antes incluso de la llegada al Senado y Dogato genovés de dirigentes abiertamente «republiquistas», los litigios en el seno de la minoría dirigente genovesa fueron frecuentes y llegaron a enfrentar las pretensiones de reforzamiento del Estado genovés con el servicio que la Monarquía Hispánica esperaba de la República. Si, por un lado, los denominados «eminenti», que como el Duque de Tursi, fiel servidor en la escuadra de galeras española, suponían un indiscutible acicate de los intereses del rey católico en el gobierno ligur, por otro lado estaban aquellos partidarios de una política de mayor distanciamiento de la órbita hispánica y que veían en los lazos financieros con la Corona española el eslabón que sumía a la República en una relación de penosa dependencia ${ }^{6}$. Ejemplos como estos apuntan a que, en cuestiones de prestigio, si bien estos particulares podían interceder en beneficio de la República, los intereses privados podían dinamitar las pretensiones del Estado ligur. Así lo afirma Thomas Kirk al referirse al dominio de los genoveses en el Mediterráneo en la década de 1590. Una hegemonía de la que participaban los particulares genoveses, pero que no siempre venía de la mano de un mayor reconocimiento internacional del gobierno de la República ${ }^{7}$.

En otro orden de cosas, el componente particular de las redes transnacionales genovesas complementa y resuelve los problemas metodológicos que pudieran derivarse de la concepción de la república ligur únicamente como una República de familias. ${ }^{8}$ Una definición limitada si se tiene en cuenta el modo de proceder genovés en el que el término «familia» se diluía en un conglomerado de filiaciones no siempre parentales que, tanto en el ámbito político como en el económico, superaban con creces la frontera del apellido común. Del mismo modo, la investigación sobre prácticas de solidaridad, asociadas frecuentemente al núcleo familiar, no deja de ser una generalidad que requiere de un análisis adaptado a cada circunstancia histórica concreta y a los perfiles de promoción priorizados o programados por el propio grupo que no siempre estuvieron a salvo de conflictos puntuales ${ }^{9}$.

sería el tío de su homónimo que posteriormente se encontrará en la Diputación del Medio General de 1608. No obstante, por ulteriores investigaciones realizadas por la autora de este artículo, sabemos que se trataba de la misma persona. Es en este sujeto en el que nos centraremos en el presente artículo. En PODESTÀ, AUGURIO, y MUSELLA, 1999: 61.

6 Una relación de dependencia que no obstante los conflictos mencionados en el seno de la clase gobernante no dejaba de compensar a partidarios y detractores. NERI, 1989: 33.

7 En KIRK, 2005:76.

8 Aunque J. Adams no tiene en cuenta el caso genovés, resulta interesante su visión sobre este asunto para las Provincias Unidas. Véase ADAMS, 2005.

9 Son muchos los casos de enfrentamientos en el seno de una misma familia. Grendi nos refiere varios de ellos para el caso de los Balbi. Véase, GRENDI, 1997: 90-92. 
El estudio del aspecto «particular» al que nos venimos refiriendo debe ir acompañado de ciertas reflexiones sobre el concepto de «red», por otro lado, casi inseparable de cualquier investigación sobre «elites transnacionales» como la que nos ocupa ${ }^{10}$. La existencia de una «sociedad multinacional» genovesa ya ha sido señalada por E. Neri que, inspirándose en los trabajos de F. Braudel, enfatizó la actuación de un grupo de banqueros financieros que, a pesar de mantener siempre vivos sus lazos con Génova, desplazaron a ésta del centro para constituir ellos, con su tupida red de informadores y colaboradores, la verdadera «bisagra» del sistema económico ${ }^{11}$. En este sentido, la red tejida por la familia Serra ${ }^{12}$ no sólo constituye un ejemplo del manejo magistral que estos hombres de negocios genoveses hacían de la jerarquía de intereses y lealtades a la República, a la Monarquía Hispánica o a la familia, concebida ésta en el sentido amplio ya referido. En definitiva, la aproximación a las familias y a los particulares genoveses nos informa de una política y economía de la República sustentadas y fuertemente influenciadas por el modo en que estos particulares gestionaban sus haciendas y negocios, mediaban por sus redes sociales, familiares y/o profesionales o solventaban las crisis haciendo uso de sus contactos a diversas escalas y de ese know-how que avalaba su protagonismo en el Imperio Hispánico ${ }^{13}$.

Para tratar los procesos de negociación informal y las estrategias de promoción de las familias genovesas en la Corte de Felipe III recurriremos al caso específico de Bautista Serra ${ }^{14}$, uno de los cuatro gentilhombres genoveses que compusieron la Diputación del Medio General (1608-1617), así como

10 Para una definición del concepto de «élite» véase MUTO, 2009:135-171:144. Para el análisis de la importancia de los individuos en estas redes de élites genovesas es de gran utilidad la metodología de análisis de redes. Al respecto, destacaremos las investigaciones de CRESPO, 2009; 2010:35-50. Otro ejemplo de su aplicación para la Edad Moderna podemos encontrarlo en cualquiera de los trabajos de J. M. Imízcoz: IMÍZCOZ BEUNZA y OLIVERI KORTA, 2010.

11 NERI, 1989:25.

12 Sobre los Serra disponemos de la monografía de E. Podestà, S. Musella y F. Augurio, ya mencionada, que cuenta con una utilísima información archivística y una elaborada genealogía. No obstante, la dimensión transnacional de la familia requiere de una revisión profunda y enriquecida con el empleo de nuevas fuentes tales como las contenidas en el Archivo General de Simancas. También es reseñable el artículo de M. Damonte que versa sobre uno de los ramos de la familia que soslayo en mi investigación. Al respecto, véase: DAMONTE, 1988, vol. VIII: 243-271. Sobre la familia en particular: BEN YESSEF GARFIA, 2011.

13 DORIA, 1986: 57-122.

14 Sobre la figura de Bautista Serra, encontramos una descripción bastante certera de su actividad al servicio de la Monarquía Hispánica en las líneas que C. Álvarez Nogal le dedica en el Diccionario Biográfico de la Real Academia de la Historia. Agradezco al investigador que me haya facilitado la lectura de este trabajo. 
agente de la República para el período de 1614-1617, en sustitución del embajador ordinario saliente Juan Jorge Marini ${ }^{15}$.

\section{LA RED SERRA A PRINCIPIOS DEL SIGLO XVII ${ }^{16}$}

Resulta indiscutible el poder de atracción ejercido por la Corte para todo aquel que desease insertarse en las redes de patronazgo regio y para un gran número de profesionales (artesanos, mercaderes, banqueros...) que la frecuentaban en su afán por obtener pingües beneficios de la ingente demanda de bienes y servicios inherente al tren de vida cortesano. Todo ello, unido al establecimiento permanente de las instituciones económicas de la Monarquía, a la centralización de los asientos en Madrid y al requerimiento de numerario por parte de la Corona y de los nobles (o aspirantes a nobles) para sus inversiones en rango y prestigio, justificó el asentamiento de una nutrida comunidad de hombres de negocios, entre los que sobresalían en número e importancia los genoveses ${ }^{17}$.

En las propias crónicas cortesanas de la época no faltan menciones a los ligures. Estos no sólo desempeñaban las funciones financieras que de ellos ha destacado reiteradamente la historiografía, sino que, gracias a su presencia en los círculos más cercanos al rey, también lo entretenían con charlas informales o juegos de mesa ${ }^{18}$. Una proximidad que les daba la oportunidad de establecer, individualmente con los ministros o con otros hombres de negocios, modos de cooperación o de resolución de conflictos que la Monarquía Hispánica mantenía con ellos o con su lugar de origen. Las formas de colaboración

15 Una relación más detallada sobre los encargos diplomáticos de los Serra se encuentra en VITALE, 1934. Bautista, después de su cargo de agente, fue destinado a Milán como enviado extraordinario entre 1617 y 1621 para discutir la cuestión de Finale y entre 1622 y 1625 volvió a Madrid, esta vez como embajador ordinario. Para esta última misión, disponemos de las instrucciones y la relación del mismo en CIASCA, 1955, vol. II:178-210. No obstante, debido a la entidad menos «formal» y provisional del cargo de agente, Ciasca no refiere ni las instrucciones ni la relación del Serra a la República para las fechas en que lo desempeñó (1614-1618), aunque sí precisa las fuentes documentales disponibles: CIASCA, 1951, vol. I: 378.

16 Para el seguimiento de este apartado, se pone a disposición del lector un apéndice final donde se presenta una selección de la genealogía de los Serra activos en los primeros años del siglo XVII y con los que Bautista Serra tenía algún tipo de vinculación. Los dos ramos que se muestran tienen su origen en Francisco Serra (1520-1570) y Pablo II Serra (1525-1579), primos entre sí. El anexo está elaborado a partir de la genealogía presente en PODESTÀ, MUSELLA y AUGURIO, 1999.

17 En HERRERO SÁNCHEZ, 46 (Madrid, 2002): 103. Sobre la presencia de los genoveses en la Corte de los Austrias, véase HERRERO SÁNCHEZ, BEN YESSEF GARFIA, BITOSSI y PUNCUH, 2011.

18 Al respecto, véase CABRERA DE CÓRDOBA, 1997: 231. 
entre banqueros genoveses se hacían patentes en la negociación de asientos en los cuales la cesión total o parcial del mismo (a través de participaciones) era práctica habitual. Así nos lo evidencia el caso del asiento de 1.243.333,3 ducados firmado por Juan Lucas Pallavicino en 1616, quien transfirió parte del mismo a Adán Centurione, Nicolao Balbi y Bautista Serra ${ }^{19}$. Del mismo modo, entre 1602 y 1615 Octavio Centurione cedió una cuarta parte de muchos de sus asientos al mismo Bautista y a Cataneo Serra, su primo ${ }^{20}$.

Pero la solidaridad entre banqueros con tratos económicos en común se manifestaba también en otros ámbitos. Es de destacar la mediación informal que estos genoveses realizaban ante los ministros reales e incluso ante el mismo monarca por algunos de sus socios de los que, en buena medida, dependía el éxito propio. En este sentido se produjo la intercesión de Ambrosio Spinola a favor de la casa comercial de Francisco Serra (hermano de Bautista y residente en Amberes donde además desempeñó el cargo de cónsul en 1607) una vez producida la bancarrota de 1607. Pulido Bueno nos refiere cómo Ambrosio Spinola había hecho relación a Felipe III «de que en la feria de Piacenza de la Aparición de 1608, Bautista y Francisco Serra debían 1.458.614 escudos de oro de marco, provenientes de dineros que habían tomado a cambio para las provisiones del ejército de Flandes, cuyos pagos corrían por cuenta del General genovés» ${ }^{21}$. La mediación de Ambrosio Spinola

19 ÁlVAREZ NOGAL, LXV/1, 219 (Madrid, 2005): 76. Las cesiones no sólo competían a los asientos de dineros, sino también a los de galeras. De hecho, en ese mismo año Adán Centurione cedió su asiento para servir con dos galeras a Juan Tomás Cambi. Para poder cumplir su cometido, Cambi hubo de hipotecar en 1620 parte de sus bienes a favor de Bautista Serra. En AGS, Contaduría de Mercedes, legajo 621, 33.

20 En ÁlVAREZ NOGAL, LXV/1, 219 (Madrid, 2005): 76. Cataneo Serra, hijo de Nicolao Serra, operaba en Madrid en los mismos años que Bautista Serra y, aunque sabemos de colaboraciones entre ambos, no tenemos constancia de que se constituyeran en compañía. De hecho, Cataneo Serra realizaba sus asientos y otros negocios desde la compañía "Cataneo Serra, Juan Benito Spinola y Juan Pedro Serra». Este Juan Pedro Serra, tío lejano de Cataneo y su cuñado, era el padre de Francisco Serra, también en Madrid, que, como se verá, actuó como ejecutor del testamento de Claudia Lomellino por poder de los hijos de ésta: Bautista, Francisco y Pablo Serra. Por su parte, Juan Benito Spinola era otro cuñado de Cataneo, casado con su hermana Paula Serra en primeras nupcias.

21 PULIDO BUENO, 2004: 253. La situación de Francisco Serra y de su socio colaborador en Amberes con el que se encontraba en compañía (Vicencio Centurione) a principios del XVII no debía pasar por sus mejores momentos aún antes de la suspensión de pagos de 1607. Precisamente, nos refiere J. Gentil Da Silva que en agosto de 1606 el Consejo de Estado debatía sobre los problemas que ambos socios manifestaban para suministrar en Flandes las cantidades con las que se habían comprometido: «[...] que Vicencio Centurione no puede cumplir la paga de los 727.250 escudos que había de dar en 5 plazos contados desde fin de agosto hasta fin de diciembre por haberle faltado según dice, sus correspondientes en la feria de Plasencia y que también habrá dificultades en cumplir Francisco Serra los 357.000 escudos que le restan pagar hasta 10 octubre, a cumplimiento del asiento que con él se hizo últimamente, que todo lo tiene en grandísimo cuidado [...]». En relación a ello, el Consejo de Estado, haciéndo- 
ante el rey sirvió para que éste accediera a la concesión de otras consignaciones que les permitieran recaudar las cantidades necesarias para satisfacer a sus acreedores. A pesar de que, en el momento en el que se declaró la bancarrota, Bautista Serra era el segundo mayor acreedor de la Corona ${ }^{22}$, no se pueden pasar por alto los beneficios que siguieron a la suspensión: el nombramiento de Bautista como uno de los diputados del Medio General de 1608 le permitió lucrarse y favorecer a las personas de su casa con juros sobre las principales rentas de la monarquía y otras prebendas. Además de ello, su introducción en esta institución constituyó toda una garantía para los privilegios de la elite financiera y gobernante de Génova. Por otro lado, la república ligur, al igual que la Monarquía Hispánica, se benefició de las habilidades de Serra, de su extensa red de contactos particulares y de sus conocimientos sobre los modos de negociación informal característicos de la Corte.

El propio ritual cortesano conminaba al establecimiento de relaciones personales reguladas por severas pautas de protocolo, jerarquía y reconocimiento del estatus que resultaban del todo necesarias para llevar a buen término un negocio ${ }^{23}$. Y precisamente, la inserción de los particulares en los círculos cortesanos, su capacidad para conformar redes de elites internacionales y el conocimiento estricto de una paradójica disciplina de la informalidad, eran algunos de los requisitos que la República genovesa estimaba cruciales a la hora de seleccionar a los ciudadanos que desempeñaran sus cargos de representación política en el exterior ${ }^{24}$.

Bautista Serra, residente en Madrid al menos desde $1602^{25}$, reunía todas las condiciones hasta ahora referidas. Su inserción en las principales redes de

se partícipe de las sugerencias del Archiduque de Austria, proponía el recurso a mercaderes portugueses con el objetivo de entretener al ejército al menos hasta finales de octubre. En GENTIL DA SILVA, 1956: 90.

22 Octavio Centurione, con 3.513.518 ducados, ocupaba el primer puesto, seguido de Bautista Serra, con 523.260 y otros 2.916 .708 por obligación del marqués Spinola; El ranking lo completaban Nicolao Balbi, con 1.544.098, y, por último, Sinibaldo Fiesco, Juan Bautista Giustiniano, y Juan Bautista y Vicencio Squarciafico, con 668.128 ducados. En DE CARLOS MORALES, 2008, (III): 799.

23 Para una profundización en las normas, significado y lenguajes del ritual cortesano, veáse ELÍAS, 1982.

24 Sobre la capacidad de los genoveses para conformar estas redes de elites transnacionales, ver el estudio pionero de GRENDI, 1997. Otros estudios reseñables al respecto: HERRERO SÁNCHEZ, 2009: 97-134. MARSILIO, LO BASSO y ÁLVAREZ NOGAL, 124/1 (Madrid, 2005): 97-110; HERRERO SÁNCHEZ y PÉREZ TOSTADO, 2010: 307-321; HERRERO SÁNCHEZ y ÁLVAREZ-OSSORIO, 2011, (I): 331-365; GARCÍA MONTÓN, 2011, (I): 367-384.

25 Podestà, Augurio y Musella lo situaban en Madrid desde 1604. En PODESTÀ, MUSELLA y AUGURIO, 1999: 99 y ss. Sin embargo, Álvarez Nogal lo localiza en esta ciudad al menos desde 1602, momento en el que lo encontramos participando en uno de los asientos más importantes suministrados por Octavio Centurione. En ÁLVAREZ NOGAL, 1997: 62. 
comunicación y financieras debe ponerse en relación con las estrategias desplegadas que se materializaron en la dispersión de la familia. Su hermano, Francisco Serra, casado con Ana Lomellini, constituía su correspondiente en la realización de asientos con destino a Flandes ${ }^{26}$. A las negociaciones de Francisco con otros banqueros genoveses habría que añadir sus contactos con mercaderes alemanes situados en Génova ${ }^{27}$. Por otro lado, no podemos dejar de destacar la posición que tenía otro hermano de Bautista Serra, Jacobo, en la Corte romana, en calidad de cardenal (desde 1611) y tesorero de la Cámara Apostólica $^{28}$. Junto a estos, cabe hacer referencia a algunos de los socios más relevantes con los que trabajaba Bautista Serra en estos años ${ }^{29}$.

La residencia de Bautista Serra en Madrid lo convertía en un representante ideal de los intereses de muchos genoveses que por cualquier razón no podían vigilar de cerca la marcha de sus intereses, entre ellos el cobro de sus rentas en la península ibérica. De ahí, se derivaron relaciones con otros ligures concretadas en cartas de poder como la concedida por Felipe Doria (hijo de Nicolao Doria) el 5 de abril de 1614 (renovada sucesivamente durante varios años) o las firmadas por algunos de sus familiares como Ana Lomellino (su cuñada) en 1616 y Claudia Lomellino (su madre) para los años de 1613 a $1619^{30}$.

${ }^{26}$ Como ya se comentó, este Francisco Serra de Amberes mantenía relaciones económicas con otros genoveses como Ambrosio Spinola y Vicencio Centurione (hermano de Octavio) y con Nicolao Pallavicino (sobre todo a partir de 1625). Esta última colaboración es referida por el mismo Nogal. Véase ÁLVAREZ NOGAL,1997: 87. Sobre los tratos de Francisco con Vicencio Centurione: PULIDO BUENO, 2004.

27 LAMBERTI, XII/I (Liguria, 1972): 72-121.

28 Los contactos de Bautista Serra con su hermano en este período se llegaron a concretar en una visita a Jacobo en Ferrara una vez que había finalizado su papel de agente de la República en Madrid. Sobre estos contactos, véase la carta que manda Serra desde Génova al secretario de Estado: Carta de Bautista Serra a Antonio Aróstegui, 21 de mayo de 1618, AGS, Estado Génova, Legajo 1934, 138, fols. 301r-302v. Jacobo se encontraba en Ferrara entre 1613 y 1623, a donde había sido destinado para perfeccionar los trabajos de la fortaleza pentagonal iniciada por el cardenal Horacio Spinola por voluntad de Clemente VIII y que quedó sin terminar tras su muerte. Véase PODESTÀ, MUSELLA y AUGURIO, 1999: 95 y 96.

29 Respecto a la colaboración de Bautista Serra con otros genoveses, sabemos de su participación en los asientos firmados por Octavio Centurione entre 1602 y 1612 . Véase ÁLVAREZ NOGAL, 1997: 62. Y también de sus negocios con Juan Lucas Pallavicino o con Nicolao Pallavicino (marqués de Mornese y casado con María Serra, su hermana) y sus descendientes, de cuyos negocios han quedado importantes huellas en la Contaduría de Mercedes del Archivo General de Simancas. A finales de los años 20 del Seiscientos, sabemos de los contratos establecidos con Francisco María Pichinotti, uno de los asentistas más destacados para el reinado de Felipe IV. Al respecto, consúltese DOMÍNGUEZ ORTIZ, 1960: 110113. SANZ AYÁN, 1988. Francisco María era hermano del también conocidísimo Andrea Pichinotti que, por otra parte, era concuñado de Nicolao Serra (tío de Bautista): el primero estaba casado con Isabela Pinelli y el segundo con María Pinelli (hermanas).

30 AGS, Contaduría de Mercedes, legajo 570 (2), 48 y 53. 
Entre todos estos individuos que nos dibujan la red de Bautista Serra, no podemos pasar por alto a su sobrino Francisco Serra, hijo de Juan Pedro Serra y también situado en Madrid en estos años. Después de la muerte de Claudia Lomellino y una vez finalizada en 1617 la misión diplomática de Bautista (que supuso su retirada provisional de la Corte y su envío inmediato a Milán) sería Francisco Serra el que recibiera varios poderes de Bautista y de sus hermanos para traspasar, vender, ceder y revocar los maravedíes de rentas de juro que tenían de su madre en Castilla31. Todo ello sin olvidar la relación de la familia con Sevilla, donde también mantenían correspondientes con el objeto de garantizar el acceso a los metales preciosos americanos necesarios para los asientos que financiaban la guerra de Flandes ${ }^{32}$. Pero las fuentes de suministro de los Serra no quedaban ahí. Los frecuentes retrasos en las llegadas de las flotas y la falta de liquidez del Estado genovés justificaban la búsqueda de numerario en otros enclaves sobre los que a nuestro juicio aún queda mucho por saber. La importancia al respecto de Venecia ya ha sido apuntada por Álvarez Nogal33 para el caso particular de los envíos de dinero a Flandes por Bartolomé Spinola en la década de los treinta del siglo XVII, así como por parte de Giorgio Doria y Maréchaux ${ }^{34}$, que nos recuerdan el papel fundamental jugado por esta República como destino de los capitales genoveses y como suministradora de metales preciosos. Aspectos de la actividad ligur que deben tenerse en cuenta a la hora de dimensionar adecuadamente la posición de Bautista Serra, quien a comienzos del siglo XVII formaba parte, junto a su hermano Pablo Serra, de la compañía de los ocho aseguradores de Venecia ${ }^{35}$.

31 Ejemplo de ello es el concedido el 20 de enero de 1620. AGS, Contaduría de mercedes, legajo 570 (1), 17.

32 La relación de los Serra con Sevilla los vincula directamente con las riquezas americanas. De hecho, durante el reinado de Felipe IV recibió consignaciones sobre los fondos de la Santa Cruzada procedentes de América. En ÁLVAREZ NOGAL, para el Diccionario biográfico de la Real Academia de la Historia. Entre sus correspondientes, destacan los nombres de Jerónimo Burone y Juan Cervino, ambos genoveses y encargados de cobrar en la Casa de la Contratación las remesas americanas consignadas a Francisco (hijo de Juan Pedro Serra) y Bautista Serra. Jerónimo Burone lo haría para dicho Francisco entre 1621 y 1622, mientras que Cervino prestaría esos servicios a su primo Bautista entre 1629 y 1638. En ÁLVAREZ NOGAL, 1997: 129. Por otro lado, tenemos constancia de la participación de Bautista Serra en el banco público Mortedo-Espinosa de Sevilla que en 1601 quebró por la mala gestión y fraudes de sus administradores: Pedro de la Torre Espinosa y el genovés Jácome Mortedo. Según J. A. Rubio, Bautista Serra se encontraba entre aquellos que habían depositado fianzas para asegurar el mantenimiento del banco. Veáse RUBIO, 24 (Madrid, 1948): 30-31.

33 ALVAREZ NOGAL, 2006: 205-232.

34 El análisis de la introducción de los ligures en estos tratos puede servir para arrojar algo de luz sobre los interesantes juegos de lealtades que manejaban estos italianos. Una profundización más precisa sobre las relaciones entre Génova y Venecia en DORIA, 1986: 91 y MARÉCHAUX, 2011: 657-693; 2012: 91-120.

35 TENENTI, 1959: 62. 
Todas estas conexiones de Bautista Serra y, en general, las de otros hombres de negocios situados en Madrid, ponen de manifiesto el cariz cosmopolita que adquirió la ciudad en esta época. La presencia de estos banqueros en la Corte madrileña contribuyó a la conexión de la urbe con las principales plazas europeas con las que mantenía contactos simbióticos que, en ningún modo, se pueden calificar de relaciones centro-periferia ${ }^{36}$.

\section{LA MISIÓN DIPLOMÁtICA DE BAUTISTA SERRA}

Bautista Serra fue escogido como representante oficial de la República en sustitución del embajador saliente, Juan Jorge Marini, que dio por finalizado su cargo el 6 de abril de 161437. El mismo 17 de abril aceptó la misión que se prolongó hasta la llegada del nuevo embajador en $1617^{38}$. Los compromisos diplomáticos que adquirió Bautista Serra como agente de la República no le eran en ese momento desconocidos. De hecho, era habitual que los embajadores contaran con el asesoramiento de otros genoveses que se encontraban en la Corte, y Bautista Serra fue una de las figuras que estuvieron presentes en la misión diplomática del anterior embajador ${ }^{39}$.

Como hemos tenido la ocasión de observar, Serra se encontraba bien conectado con algunos de los personajes más destacados de la época y su posición en la Corte le permitió conocer al detalle los entresijos del poder. El trato particular con cada uno de estos individuos de la Corte madrileña se venía produciendo sin duda desde mucho antes de que la República lo invistiera oficialmente como su agente, hecho que encuentra un ejemplo clarificador en las negociaciones personales que Bautista Serra y otros banqueros genoveses sostuvieron con el ministro Pedro Franqueza, Conde de Villalonga, y con

36 Álvarez Nogal destaca cómo precisamente los genoveses ubicados en Madrid mantuvieron mayores contactos con sus socios situados en otros enclaves europeos que con aquellos localizados en otras ciudades castellanas. ÁLVAREZ NOGAL, 2000: 133.

37 Para la misión diplomática de Serra, véase Lettere del eccelentissimo Serra al Serenissimo governo di Genova, ASGe, Archivio Segreto, legajo 2427, Lettere Ministri Spagna.

38 El 10 de marzo de 1616 se enviaron las instrucciones a Felipe Adorno, el sustituto previsto de Serra. Pero Felipe Adorno, nombrado embajador ordinario el 26 de febrero de ese año, murió a finales de abril, antes de embarcar a España para el desempeño de su cargo. CIASCA, 1951, (I): 385. Finalmente, la llegada de Juan Bautista Saluzzo como nuevo representante oficial de la República, relevó a Serra de su misión el 9 de junio de 1617, momento en el que Saluzzo presentó sus credenciales en Madrid. CIASCA, 1951, (I): 390.

39 Bautista Serra, junto a Ambrosio Spinola, Sinibaldo Fiesco y Octavio Centurione, fue una de las figuras recomendadas por la República el 10 de septiembre de 1613 a Juan Jorge Marini para tratar sobre el asunto de Finale. Nos lo revelan las instrucciones enviadas por Génova a Felipe Adorno en 1616 cuyo principal cometido era la recuperación de este enclave importante. Como comentamos, Felipe Adorno nunca llegó a ocupar el cargo. CIASCA, 1951, ( I): 388. 
Alonso Ramírez de Prado, figuras protagonistas de la Junta del Desempeño (1602-1607) y de uno de los mayores escándalos financieros de principios del reinado de Felipe III. El conocimiento del ámbito cortesano en el que se estaban produciendo las demandas de la República es fundamental para entender los obstáculos y los apoyos con que contaba el agente ${ }^{40}$. No en balde, Serra dedicó gran parte de sus cartas a transmitir al gobierno genovés la posición que manifestaban los ministros del rey hacia la República.

Las circunstancias de tensión protocolaria aderezadas con la desconfianza de la República ante su socio hispánico provocaron actitudes de animadversión hacia los genoveses por parte de algunos de los consejeros y allegados más influyentes del rey. Éstas no sólo se atisban en las opiniones vertidas en el Consejo de Estado, sino también en las afirmaciones de algunos ministros y personajes de la Corte que Bautista Serra recogió por referencias de terceros. En esta tesitura parece haberse encontrado la Condesa de Lemos que, según había sido informado Bautista Serra, habría comparado el indecoroso comportamiento de la República en el enfrentamiento de 1614 por una tartana del Duque de Osuna con el mantenido años antes por parte de Venecia con el Papa que desembocó en el interdicto papal de $1606^{41}$. Los recelos que suscitaba Venecia y, sobre todo, los conocidos tratos entre los ligures y la república enemiga se hicieron patentes en otras ocasiones. En abril de 1616, Bautista Serra escribía al gobierno genovés para manifestar el disgusto que el secretario Aróstegui le habría transmitido por la posibilidad de que hubiera genoveses sirviendo a la propia Venecia ${ }^{42}$. Nueve meses después, Bautista comunicaba al Senado genovés la prohibición expresa que se habría dado a Nápoles de que contratara con venecianos por los suministros que estos italianos estarían brindando a Saboya ${ }^{43}$. Precisamente, la guerra con Saboya, uno de los

40 Existe una abultada bibliografía al respecto. En este sentido, no puede pasarse por alto el reciente estudio sobre la Corte de Felipe III llevado a cabo bajo la dirección de J. Martínez Millán y M. A. Visceglia que recoge una excelente selección de aportaciones de diversos especialistas. MARTÍNEZ MILLÁN y VISCEGLIA, 2008/2009, 4 vols.

41 Carta de Bautista Serra a la República, 3 de mayo de 1614, ASGe, Archivio Segreto, legajo 2427, Lettere Ministri Spagna. Dice literalmente Serra: «E perchè da certa parte hebbi notizia che la contessa de Lemos haveva detto che nel toccante della tartana si era governata la repubblica in modo che quella di Venetia non haveria potuto far peggio con Sua Santità, hebbi per bene d'andarla a ritrovare subito come fecci, dolendomi che non essendo informata della verità, condanassi a Vostre Serenissime del loro zelo verso le cose di Sua Maestà mentre che si dovevano grazie, però che da una impressione simile da sua eccelenza, cansata da relationi false tanto più conosceva quanto fossi neccessario il remedio alla causa di dove procedeva, e li diedi conto dogni cosa $[\ldots] \gg$.

${ }^{42}$ Carta de Bautista Serra a la República, 11 de abril de 1616, en ASGe, Ibidem.

43 Carta de Bautista Serra a la República, 18 de enero de 1617, ASGe, Ibidem: «i disgusti che passano con venetiani per il denaro particularmente che pagano a Savoya, son già 
grandes acontecimientos recogidos por Serra en sus cartas, sería motivo de nuevas rencillas entre los ministros del rey y Génova ante las razones que esta última argüía para eximirse de la aportación de tropas a Milán: la necesidad de autodefenderse de la propia Saboya ${ }^{44}$.

Más enérgico en sus objeciones hacia la República era el Duque del Infantado al que Serra definía como colérico y poco inclinado a los intereses de los genoveses. Son muchas las referencias que el agente nos aporta de este personaje, pero su presencia cobra mayor relevancia en asuntos como la mencionada tartana del Duque de Osuna (del cual era defensor), la precedencia de las galeras de Malta sobre las genovesas y la cuestión, también protocolaria, de la anticipación del saludo por parte de la ciudad de Génova al estandarte real. Este último asunto se habría desencadenado por el agravio infligido al príncipe Filiberto, General del Mar de Su Majestad, que se habría negado a entrar en el puerto de Génova por no haber sido saludado previamente por esta ciudad $^{45}$. El Duque del Infantado se mostraba totalmente contrario a las explicaciones de la República sobre la existencia de precedentes que validaran la actuación de las autoridades genovesas y ante tales argumentos manifestaba que «[...] questi sono degli guadagni che fa il Ré di dar carrichi agli stranieri, et altre cose simili» ${ }^{46}$. Por lo que se refiere a la cuestión de la precedencia de las galeras de Malta sobre las genovesas, fue el propio Aróstegui el que recomendó a Bautista Serra que estuviera vigilante para que en el Consejo de Estado en el que se discutiera el asunto se encontrara el Marqués de Velada y no el Duque del Infantado, conocido bien afecto a la causa de la Orden de Malta $^{47}$.

Vistos algunos de los acontecimientos aquí referidos y recogidos por la correspondencia de Bautista Serra a la República, podemos inferir que el senti-

qualche giorni che stimo sia andato ordine in Napoli per impedire la total contratacione di detto Reyno con detti venetiani».

${ }^{44}$ No faltan en la correspondencia de Serra numerosas alusiones a la necesidad que en este momento tenía la República de salvaguardarse de los peligros de la guerra con Saboya. Discursos que deben enmarcarse en el contexto de desconfianza hacia la capacidad del monarca hispánico de defender la libertad genovesa, así como en el deseo de Génova de hacer valer su prestigio internacional mediante meras acciones de presión a su aliado ante la inviabilidad de cualquier otra demostración de fuerza más directa.

45 Como defensa ante las acusaciones de ingratitud por parte de Filiberto, el Senado mandó a Serra el 21 de agosto de 1614 la «Relatione de'complimento et ricevimenti fatti dalla Repubblica al Principe Filiberto Generale del Mare per la Maestà Cattolica» para que con ella consiguiera convencer a la corte española de la inconsistencia del enfado del General. Carta de la República a Serra, 21 de agosto de 1614, ASGe, Ibidem.

46 Carta de Bautista Serra a la República, 12 de octubre de 1614, ASGe, Ibidem.

47 La importancia del voto del Duque del Infantado ya fue recogida en los escritos de S. Contarini con estas palabras: «Es de gran consideración ganar este voto porque sabe defenderlo en el Consejo de Estado donde tiene autoridad y mano». En CONTARINI, 2001: 58. 
miento anti-genovés era en los primeros años del Seiscientos una realidad ${ }^{48}$. Al margen de conflictos sonoros de esta época mantenidos entre la Monarquía Hispánica y Génova, como el enfrentamiento por Finale, la precedencia de las galeras de Malta sobre las ligures o las tensiones derivadas de la guerra con Saboya, nos centraremos en esta ocasión en uno a priori minúsculo que aflora de entre las muchas misivas escritas por Bautista Serra: se trata del ya citado asunto de la tartana del Duque de Osuna, apresada por corsos en Sestri y cuyos ocupantes ( 20 soldados, 12 marineros y el alférez Jerónimo del Valle) fueron llevados ante el gobernador de Chiavari por las sospechas de que pudieran ser «vascelli di ladri et corsari sotto specie d'amici» 49 .

A pesar de que no conocemos la fecha de comienzo del litigio, sabemos que se trataba de un conflicto no resuelto por el antecesor de Serra, Juan Jorge Marini ${ }^{50}$. En el momento en el que Bautista Serra aceptó representar a la República (el 17 de abril de 1614) el ambiente se encontraba ya caldeado por las duras represalias adoptadas por el virrey Duque de Osuna contra la comunidad genovesa de Sicilia. Asunto que fue discutido en una consulta de Estado del 15 de marzo de 1614 y que dejan traslucir las cartas furibundas escritas por el embajador español en Génova, Juan Vivas, al Duque de Osuna, incitándole a ejecutar un contundente castigo contra los ligures. En concreto, el virrey de Sicilia comunicaba al rey que había ordenado por bando público el confinamiento de los genoveses de Palermo y Mesina en sus casas hasta nueva orden «permitiendo que los menestrales y demás gente pobre puedan ejercer sus oficios no saliendo de la tierra y los mezanos que traten los cambios y demás negocios tocantes a la hacienda $[\ldots]\rangle^{51}$. Pero el desquite no quedó ahí.

48 Del mismo modo, en la República se materializaron esos resquemores en escritos que nos transmiten la existencia de un malestar hacia lo español que, si aún no posee las dimensiones del que caracterizará a las décadas de 1630 y 1640, supusieron la antesala del programa de autonomía y de distanciamiento de la alianza hispánica desarrollado posteriormente por los llamados «republiquistas». Al respecto, véase COSTANTINI [et alii], 1976.

49 En Carta del Duce y gobernadores de Génova al Duque de Osuna, 29 de enero de 1614, AGS, Estado Sicilia, legajo 1167, 27. De nuevo, detrás de estas palabras se vislumbra el discurso de autodefensa referido por la República para exculparse. Un argumento que, según el marqués de Villafranca en una de las consultas emitidas por el Consejo de Estado, no debía de interpretarse como una excusa, sino como una comprensible prevención ordinaria en una época en la que «por todas [las costas] andan moriscos en hábito de españoles». En Consulta del Consejo de Estado, 10 de mayo de 1614, AGS, Estado Sicilia, legajo 1168, 181.

50 En CIASCA, 1951, (I): 382 y 383.

51 Carta del Duque de Osuna al rey, 7 de marzo de 1614, AGS, Estado Sicilia, legajo 1167, 26. El atentado contra los privilegios de la comunidad genovesa de Sicilia, en concreto contra aquella de Palermo, fue un duro varapalo contra uno de los principales colectivos que apoyó al virrey en las medidas aprobadas por éste en 1612. Unas medidas en torno a las que se aglutinaron las fuerzas interesadas en «salvaguardar para la isla el mantenimiento de un papel de gran exportadora de trigo y en defender el centralismo de la capital como imán de la inmo- 
«[...] Aunque hubiera sido justo embargalles sus haciendas por no tocalles en el crédito lo excusado» ${ }^{52}$, el Duque de Osuna se contuvo en esta ocasión de aplicar una medida que sin duda hubiera derivado en consecuencias nefastas en un momento en el que la Monarquía Hispánica requería la colaboración de la República para llevar a buen término la guerra de sucesión del Montferrato. Esta posibilidad de ejecutar una confiscación de bienes a los genoveses en los territorios hispánicos constituye un claro antecedente de otras incautaciones que la Corona española haría efectivas más adelante con motivo del enfrentamiento con la República por los derechos que el banco de San Jorge de Génova se atribuía sobre la sal de Finale ${ }^{53}$.

No obstante, el agravio ocasionado a la Corona requería según el virrey de una demostración mayor: Serra nos informa que, por decreto de 14 de agosto de 1614, el Duque de Osuna mantenía en la cárcel a los cónsules genoveses de Palermo y Mesina ${ }^{54}$.

El enfrentamiento, a pesar de su corta duración (fue resuelto el 21 de octubre de 1614 con la liberación de los cónsules) supuso la demora de asuntos

vilización de la renta y los gastos suntuarios. Es decir, en primera fila la nobleza feudal productora de cereales, la universidad de Palermo y la colonia genovesa de la capital que controlaba el comercio de trigo» En BENIGNO, 1994: 87 y 88.

52 Carta del Duque de Osuna al rey, 7 de marzo de 1614, AGS, Estado Sicilia, legajo $1167,26$.

53 Concretamente, nos referimos al encarcelamiento de Esteban Balbi, genovés residente en Milán, y a la confiscación de las rentas que los Protectores de San Jorge tenían en el reino de Nápoles, medida adoptada en 1639 por el Marqués de Leganés, gobernador de Milán, ante la detención por parte de las autoridades genovesas de un súbdito finalino acusado de contrabando de la sal. Véase, GRENDI, 1997: 176. Posteriormente, en 1654, el Marqués de Caracena, gobernador de Milán, publicaba una ordenanza real por la que se decretaba el embargo de los bienes y rentas de los genoveses en los territorios italianos de la Monarquía Hispánica con el objetivo de imponer a Génova la liberación de las naves finalinas que había apresado un año antes. Al respecto, véase HERRERO SÁNCHEZ, LXV/1, 219 (Madrid, 2005): 115152:141 y BITOSSI, 2011, (II): 495-526.

${ }_{54}$ Carta de Bautista Serra a la República, 12 de octubre de 1614, ASGe, Archivio Segreto, legajo 2427, Lettere Ministri Spagna. Por carta de la República a Serra de 26 de marzo de 1614 se nos informa de que los cónsules encarcelados eran Nicolao Cavana y Camilo Pallavicino, cónsules de la nación genovesa en Palermo. Sobre estos dos cónsules, VITALE, 1934:242. El encarcelamiento de estos supuso el fin del enclaustramiento en sus casas de la comunidad genovesa de Mesina y Palermo. En Carta del Duque de Osuna al Rey, 11 de mayo de 1614, AGS, Estado Sicilia, 1167, 32. La carta fue vista en Consejo de Estado en el que se concluyó la retención del cónsul hasta que la República castigara a los culpables de la ofensa. Algunos, como el Duque del Infantado, proponían un paso más: «que si no dan satisfacción se hará la demostración que convenga donde quiera que se hallaren galeras suyas, que don Carlos Doria escribe muy sucintamente en esto y se le podía ordenar que acuda al remedio de ello y a todo lo que se ofreciese como se espera». En Consulta de Estado, 15 de marzo de 1614 [en la que se vio lo que escribieron el embajador Juan Vivas y el Duque de Osuna], AGS, Estado Sicilia, legajo 1168, 176. 
más importantes para la República como la cuestión de Finales, puesto que sobre este suceso sólo debía discutirse «ad animi quieti e fuori di ogni turbatione e lasciarlo a tempo oportuno» ${ }^{55}$.

El caso es interesante por varias cuestiones ya destacadas a lo largo de este artículo. En primer lugar, por poner en evidencia el papel jugado por los particulares de la República que en las cuestiones más protocolarias en las que se decidía el prestigio del Estado ligur no se mostraban tan unidos como pudiera haber ocurrido ante una amenaza de suspensión de pagos de la Corona. En situaciones como estas, las fidelidades de estos particulares entraban en juego y se ponían al servicio del socio que se revelaba más interesante en ese instante preciso. En la documentación manejada, Carlos Doria, Duque de Tursi, y el cardenal Juanetín Doria, individuos más que conocidos por su pertenencia al grupo de los «eminenti» al servicio del monarca español, se posicionaban del lado de Juan Vivas y del Duque de Osuna ${ }^{56}$. Bautista Serra y Octavio Centurione, que aparecía extraoficialmente en el «carteggio» del agente como figura mediadora entre el Duque de Lerma y los intereses de las autoridades ligures, representaban los objetivos de la República. El primero, atendiendo a

55 Así lo hizo saber la República a Felipe Adorno en las instrucciones a él enviadas en 10 de marzo de 1616. En éstas, que iban fundamentalmente encaminadas a la recuperación de Finale, la República refería a Adorno el envío a finales de diciembre de 1613 de un memorial al embajador precedente (Juan Jorge Marini) con el objeto de que lo entregara a Su Majestad y procurar así una pronta restitución del enclave. No obstante, el desencuentro con el Duque de Osuna (informaba la República a Felipe Adorno) habría obligado a posponer el asunto debido a la dificultad de obtener una solución favorable en un contexto de clara animadversión hacia los genoveses, resultante del apresamiento de la tartana. En CIASCA, 1951, (I): 389.

56 El 15 de marzo de 1614 se vería en Consejo de Estado una de las cartas escritas por el embajador español en Génova al Duque de Osuna en la que Vivas recomendaba al virrey de Sicilia que escribiera al Duque de Tursi para que él y su sobrino se esforzaran, haciendo uso de sus deudos y amigos, por incentivar la «libertad de los buenos» en aquella república. En Consulta de Estado de 15 de marzo de 1614, AGS, Estado Sicilia, legajo 1168, 177. Por otro lado, y en relación a la «división» del patriciado de la República, en otra de estas cartas, Juan Vivas hacía referencia a cómo el príncipe Doria era maltratado por «envidiosos» que deseaban «abajar aquella casa y procuran en cuanto pueden la igualdad y sobre todo le dan en rostro que tengan en su casa guardia de alabarderos mi señor, a la princesa y el príncipe y así para dar principio a barajar aquello pidieron a mi señora la princesa y a don Carlos y a mí que diésemos nómina en escrito de los criados que teníamos que podrían llevar armas [...]». Un maltrato a los ciudadanos favorables a la Monarquía Hispánica que vendría acompañado de la «ingratitud de esta nación a Su Majestad y a la nación española que llega a término que mozuelos locos se topan españoles en las calles, les hacen cosas y se ríen de ellos [...]». Carta de Juan Vivas al Duque de Osuna, 28 de marzo de 1614, AGS, Estado Sicilia, legajo 1167, 33. Esta argumentación de Vivas entronca, como puede observarse, con la demanda incisiva del agente de la República en Madrid a los ministros del rey para que obligaran al embajador español en Génova a entregar al Senado ligur la lista de personas que se encontraban a su servicio (el llamado «rolo» o «rolli»). Demanda presente en varias cartas de Serra a la República en el fondo ya comentado: ASGe, Archivio Segreto, legajo 2427, Lettere Ministri Spagna. 
las instrucciones de la República, justificó su defensa en la disculpa de la actitud del capitán de Chiavari, que, al contrario de lo aludido por Vivas y el Duque de Osuna, habría liberado a los españoles una vez aclarado el asunto sin haber previamente infligido ningún tipo de maltrato a los ocupantes de la nave ni al estandarte real, ni haber saqueado las mercancías transportadas, como aducía el virrey de Sicilia. Por otro lado, la implicación de Octavio Centurione nos evidencia la influencia que el hombre de negocios continuaba contando en la Corte a pesar del pleito que pesaba sobre él desde 1609 y que no le impidió la obtención de nuevas mercedes del patronazgo regio, como su nombramiento como Duque de Gravina en $1610^{57}$. No obstante lo hasta aquí expuesto, las circunstancias descritas no dejaban de ser situaciones puntuales que no excluían de la posibilidad de un posicionamiento diverso, mediatizado por los beneficios que de él pudieran derivarse, en unas condiciones diferentes. Lo cual nos lleva a preguntarnos por el modo en que interaccionaban y se complementaban estas lealtades, en qué condiciones podían entrar en conflicto y los intereses subyacentes que podían conducir a la priorización de una sobre la otra en las distintas coyunturas ${ }^{58}$.

La homogeneidad de criterio tampoco fue la nota característica entre los ministros del rey. La actitud «reputacionista» y extremista del Duque de Osuna halló férreos apoyos en la Corte en el Duque de Uceda y en el Duque del Infantado, y en Génova en el embajador Vivas; todos ellos exigían una acción demostrativa por parte de la República como requisito previo a la liberación de los cónsules genoveses ${ }^{59}$. La actitud de Juan Vivas fue más reprobada que

57 SANZ AYÁN, 2011, (II): 847-872.

58 El largo litigio que Bautista Serra y sus sucesores sostuvieron con la Monarquía Hispánica por el mantenimiento de la «perpetuidad», comprada en 1617, para el desempeño del oficio de Correo Mayor de Milán no es más que un ejemplo de cómo las fidelidades no tenían por qué entrar en conflicto, sino que éstas se utilizaban y se actualizaban adaptándose al momento específico. Ver BEN YESSEF GARFIA, 2011, I: 303-330. La posible existencia de una incompatibilidad entre el servicio a la Corona española y el desempeño de cargos en Génova se vislumbra en una de las cartas del embajador español en la República al rey. Refiriéndose a los resultados de una reunión de las autoridades genovesas comunicaba que «han renovado en esta junta la ley que ningún vasallo suyo pueda servir a otro príncipe por tiempo de cinco años pena de confiscación de bienes y bandido della». En Carta del Marqués de Castañeda, 6 de diciembre de 1624, AGS, Estado Génova, legajo 1936, 242, fol. 497v.

59 No deja de ser curioso que, si bien se conminaba a Génova a la imposición de algún castigo a los culpables, su agente aclaraba al Senado ligur que también se había decidió que el embajador Juan Vivas no debería comprobar si finalmente las autoridades habían actuado o no contra los culpables. En Carta de Bautista Serra a la República, 16 de julio de 1614, ASGe, Archivio Segreto, legajo 2427, Lettere Ministri Spagna. La República atendió a estas demandas como se deduce de la misiva enviada a Bautista Serra el 19 de septiembre de 1614 en la que se le hacía saber del nombramiento de un comisario, Felipe Cattaneo, para la realización de las averiguaciones pertinentes sobre lo que había ocurrido en Sestri y Chiavari. Con los resultados de estas indagaciones la República había redactado un memorial que envió a su 
la de Osuna, tanto por el resto de los consejeros de Estado como por el mismo Bautista Serra. Mientras que el Duque de Osuna fue simplemente reprendido por no haber esperado el parecer del rey antes de arremeter contra los genove$\operatorname{ses}^{60}$, a Juan Vivas se le reprochó duramente por haber alentado los ánimos del virrey sin suministrar ninguna prueba de lo que había sucedido verdaderamente en Sestri, indisponiendo a la República, reavivando antiguas rencillas entre viejos y nuevos al implicar a la casa Doria y provocando, en última instancia, la reacción exaltada del virrey ${ }^{61}$.

Todos los elementos nos hacen relativizar las distancias que comúnmente se establecen entre sistemas dinásticos y republicanos. El tratamiento directo con y entre particulares podía abreviar la resolución de los procesos y dinamizar las negociaciones, además de permitir el aprovechamiento de las cualidades y recursos individuales de los implicados. Ventajas que explican en parte hechos como la preferencia de la Monarquía Hispánica por contratar con privados genoveses la composición de su escuadra de galeras ${ }^{62}$ o el inte-

agente y que, insistía, no convenía que entregara a los ministros españoles, sino que lo habría de transmitir oralmente. En él, el gobernador de Chiavari era de nuevo exculpado, justificando su actuación en los disparos realizados desde los barcos con intención provocadora por los españoles. En Carta de Bautista Serra a la República, 19 de septiembre de 1614, ASGe, Archivio Segreto, legajo 2427, Lettere Ministri Spagna.

60 Carta del Serra a la República, 16 de julio de 1614, ASGe, Ibidem. En general, las opiniones sobre el Duque de Osuna que se traslucen de las consultas del Consejo de Estado son bastante recatadas incluso por parte de aquellos que, como el cardenal y arzobispo de Toledo, se mostraban favorables a la causa de la República. Así, el mencionado cardenal declaraba que había sido excesiva la demostración del Duque pero «tiene por forzoso que a los que están en oficios mayores se han de favorecer sus acciones y así remitirá al duque el negocio encargándole que disponga en él con la cordura y paciencia que de él se fía». El Marqués de Villafranca, aunque demandaba a la República una acción de castigo contra el capitán de Chiavari y consideraba que el Osuna no había hecho mal en prender a los genoveses, sugería que el virrey podía haber sido más moderado en su actitud. En Consulta de Estado, 28 de abril de 1614, AGS, Estado Sicilia, legajo 1168, 181. En lo que respecta al Marqués de la Laguna, que creía que «contemporizar tanto con italianos causa estos desconciertos y será peor cada día si no se previene y remedia», no era de extrañar que también excusara tan gran demostración. En Consulta de Estado, 15 de marzo de 1614, AGS, Estado Sicilia, legajo 1168, 176 y Consulta de Estado, 28 de abril de 1614, AGS, Estado Sicilia, legajo 1168, 181.

61 Varios fueron los ministros que acusaron a Juan Vivas de cegarse por fines vengativos que perjudicaban la relación del rey con la República. El Marqués de Villafranca fue uno de los que más detalló los motivos que hacían a Juan Vivas merecedor de una reprimenda: «está con pasión por la reformación de las armas de sus criados» y por otro lado es «de notar que don Juan está tan apasionado contra la república que desea cosas contra sí por vengarse de ella».Consulta de Estado, 10 de mayo de 1614, AGS, Estado Sicilia, legajo 1168, 181.

62 «Ciò può sembrarci assurdo, ma lo Stato trovava più efficace in termini di spesa (penso sia questo il moderno eufemismo), cioè più conveniente e meno problematico, trattare con imprenditori privati (e in tal modo avere a che fare anche col loro affarismo) che dirigere in proprio l'intera flotta». Véase CALABRIA, 1994: 285. 
rés de Marcos Antonio Sauli por la negociación con particulares, y no con el Estado de Génova, de un estanco de especias en régimen de monopolio con la Corona española ${ }^{63}$. Como se ha visto, la negociación a través de particulares más que una característica exclusiva de la República impregnaba el sistema político del Seiscientos. Pero no por ello se pueden obviar las consecuencias que el fenómeno originaba en el funcionamiento de las instituciones republicanas genovesas y, en general, en la entidad del Estado ligur. Una república gobernada por una elite de oligarcas que, a diferencia de otras como la de Venecia basó su éxito, y con él el de la República que gestionaban, en formas más flexibles de acumulación de capital que atendían a sus intereses privados, si bien condicionados en todo caso por la coyuntura internacional ${ }^{64}$. La unión de lo público y lo privado permitió al Estado valerse de las fortunas y cualidades de los ciudadanos pertenecientes al ceto dirigente, pero en ello no dejaba de descubrirse la gran debilidad de un Estado sujeto a fines particulares que no siempre garantizaban acciones conjuntas para salvaguardar el estatus de la República ${ }^{65}$.

Por otro lado, el caso aquí presentado permite la observación de los mecanismos de negociación de esta época, a través de los cuales se vislumbra un funcionamiento de la política internacional por parámetros que nada tienen que ver con la existencia de un centro que impone y una periferia que acata. En esta característica no sólo es determinante la definición de la Monarquía Hispánica como un «imperio negociado» ${ }^{66}$, sino también la conciencia de que la negociación era frecuentemente mucho más que un acuerdo bilateral. Más bien, antes de la llegada a un marco compartido se había producido la intervención de múltiples sujetos: consejeros de Estado, burócratas, embajadores, cónsules, virreyes, hombres de negocios, personajes influyentes de la Corte, ... sin cuya mediación, opinión e iniciativa no se puede entender la toma de decisiones ni la resolución o complicación de los conflictos en la Europa del momento.

Los éxitos adquiridos por Bautista Serra durante y después de su misión como agente nos dejan claro que el genovés supo aprovechar los contactos trazados y la influencia alcanzada en la Corte madrileña durante el ejercicio del cargo. En 1617 consiguió la perpetuidad del oficio de Correo Mayor de Milán ${ }^{67}$; los beneficios para su casa derivados de su participación en la Dipu-

63 En PACINI, 2008, (III): 1114.

64 ARRIGHI, 1999: 136.

65 Este modo de proceder por parte de los particulares genoveses tiene implicaciones importantes en el pensamiento económico del siglo XVII que ya fueron apuntadas por Felloni. Véase FELLONI, 1999: 1340.

66 GREENE, 1994.

67 Concretamente, el privilegio se le concedió el 6 de diciembre de 1617 y con motivo de los servicios financieros prestados en el pasado por él y su hermano Francisco Serra para el costeamiento de la guerra en los Países Bajos. La maniobra pudo estar orientada no sólo a 
tación del Medio General fueron también conspicuos y, como agente de la República, adquirió una posición desde la que recompensar a viejos y a nuevos clientes. Sin olvidar que sus funciones de agente le brindaron la posibilidad de valerse de las autoridades genovesas como catalizadora de sus fines en Génova.

En definitiva, no puede minusvalorarse el papel de los ciudadanos genoveses que operaban como representantes oficiales de la República, lo cual no era óbice para el despliegue contemporáneo de estrategias particulares, en beneficio propio y de los de su red, desarrolladas en planos más informales. En este modo de actuar, si bien podría hallarse en circunstancias puntuales el propio talón de Aquiles de la República, se encontraba también la base del enorme poder de negociación que ostentaba Génova en la escena europea y la razón del éxito de su alianza con la Monarquía Hispánica hasta finales del siglo XVII.

recompensar a la casa Serra, sino a procurarse su apoyo para el importante asiento firmado por la Corona muy poco después (el 29 de diciembre de 1617) con Octavio Centurión y el resto de los Diputados del Medio General (entre ellos, Bautista Serra) para proveer de un millón de escudos en Flandes. En AGS, Dirección General del Tesoro, Inventario 11, legajo 3-2. 


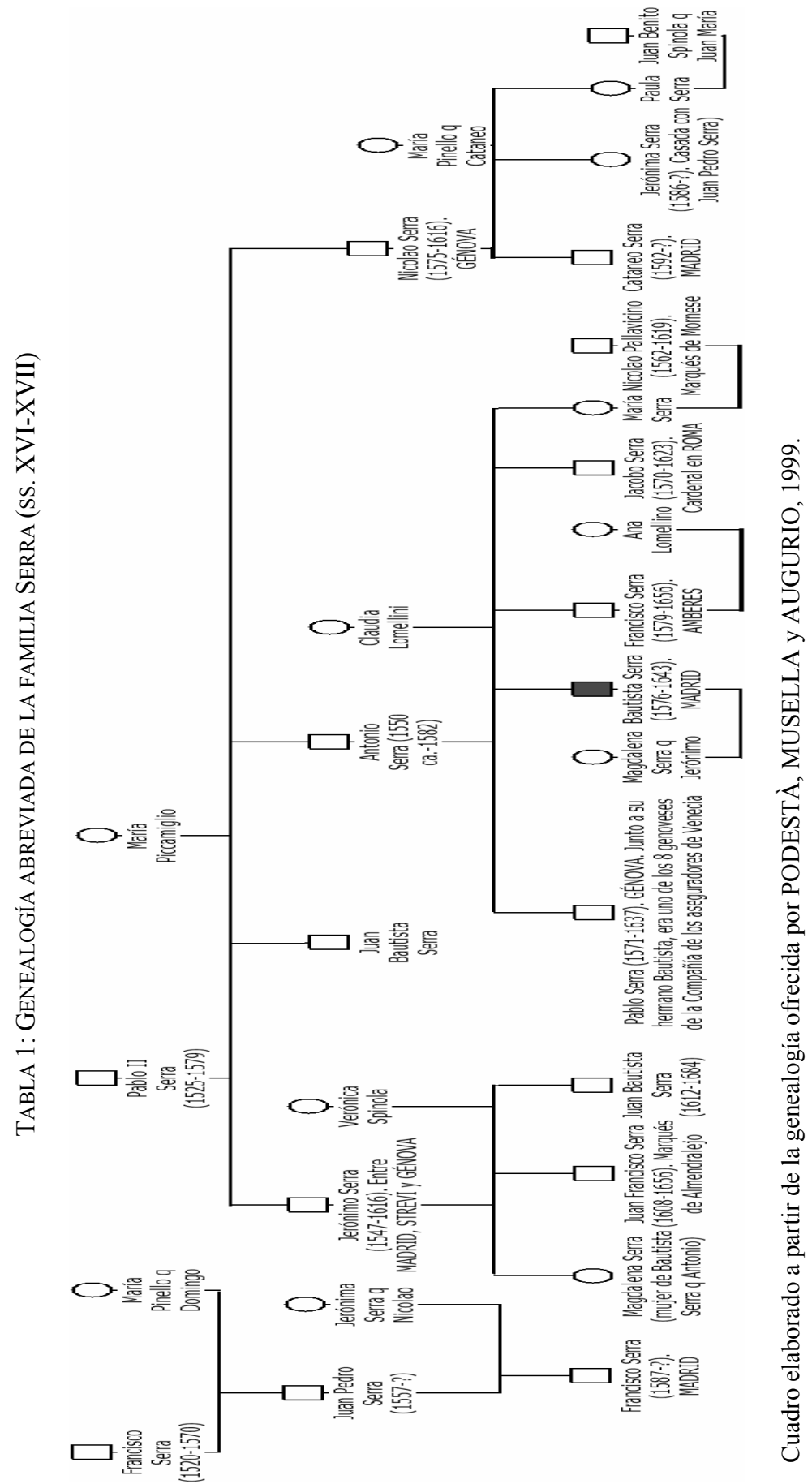




\section{Bibliografía}

Adams, Julia, The Familial State and Merchant Capitalism in Early Modern Europe, Nueva York, Cornell University Press, 2005.

Álvarez Nogal, Carlos, "Bautista Serra", Diccionario biográfico español, Madrid, Real Academia de la Historia, 2009 (en prensa).

Álvarez Nogal, Carlos, Los banqueros de Felipe IV y los metales preciosos (16211665), Madrid, Banco de España, 1997.

Álvarez Nogal, Carlos, Sevilla y la Monarquía Hispánica en el siglo XVII, Sevilla, Ayuntamiento de Sevilla, 2000.

Álvarez Nogal, Carlos, "Las compañías bancarias genovesas en Madrid a comienzos del siglo XVII", Hispania, LXV/1, 219 (Madrid, 2005): 67-90.

Álvarez Nogal, Carlos, "La transferencia de dinero a Flandes en el siglo XVII", en Bernardo José García García y Carmen Sanz Ayán (eds.), Banca, crédito y capital. La Monarquía Hispánica y los antiguos Países Bajos (1505-1700), Madrid, Fundación Carlos de Amberes, 2006; 205-232.

Arrighi, Giovanni, El largo siglo XX. Dinero y poder en los orígenes de nuestra época, Madrid, Akal, 1999.

Benigno, Francesco, La sombra del Rey, Madrid, Alianza Editorial, 1994.

Ben Yessef Garfia, Yasmina Rocío, "La república de Génova, sus particulares y la negociación del conflicto en el reinado de Felipe III", en Bernardo José García García, Manuel Herrero Sánchez y Alain Hugon (dirs.), El arte de la prudencia. La Tregua de los Doce Años en la Europa de los Pacificadores, Madrid, Fundación Carlos de Amberes, 2012; 121-144.

Ben Yessef Garfia, Yasmina Rocío, "Entre el servicio a la corona y el interés familiar. Los Serra en el desempeño del oficio del Correo Mayor de Milán (1604-1692)”, en Manuel Herrero Sánchez, Carlo Bitossi, Yasmina Rocío Ben Yessef Garfia y Dino Puncuh (eds.), Génova y la Monarquía, 1528-1713, Génova, Atti della Società Ligure di Storia Patria, Nuova Serie, LI (CXXV), fasc. I, 2011, (1): 303-330.

Bitossi, Carlo, «Il granello di sabbia e i piatti della bilancia. Note sulla politica genovese nella crisi del sistema imperiale ispano-asburgico, 1640-1660», en Manuel Herrero Sánchez, Carlo Bitossi, Yasmina Rocío Ben Yessef Garfia y Dino Puncuh (eds.), Génova y la Monarquía, 1528-1713, Génova, Atti della Società Ligure di Storia Patria, Nuova Serie, LI (CXXV), fasc. I, 2011, (2): 495-526.

Cabrera de Córdoba, Luis, Relaciones de las cosas sucedidas en la corte de España desde 1599 hasta 1614, Salamanca, Junta de Castilla y León, 1997.

Calabria, Antonio, "Finanza e stato. Un commento", en Giorgio Chittolini, Anthony Molho y Pierangelo Schiera (dirs.), Origini dello Stato. Processi di formazione statale in Italia fra medioevo ed età moderna, Bolonia, Il Mulino, 1994; 281-286: 285

Canosa, Romano, Banchieri genovesi e sovrani spagnoli tra Cinquecento e Seicento, Roma, Sapere, 2000. 
Ciasca, Raffaele, Istruzioni e relazioni degli ambasciatori genovesi. Spagna (14941617), Roma, Istituto Storico Italiano per l'età moderna e contemporánea, 1951 (I).

Ciasca, Raffaele, Istruzioni e relazioni degli Ambasciatori genovesi. Spagna (16191635), Roma, Istituto Storico Italiano per l'età moderna e contemporánea, 1955 (II).

Contarini, Simone, Estado de la monarquía española a principios del siglo XVII, Málaga, Editorial Algazara, 2001.

Costantini, Claudio [et alii.], Dibattito politico e problemi di governo a Genova nella prima metà del Seicento, Florencia, La Nueva Italia, 1976. Extraído de Miscellanea Storica Ligure, VII/2 (Liguria, 1975).

Crespo, Ana, Mercaderes atlánticos: redes del comercio flamenco y holandés entre Europa y el Caribe, Córdoba, Universidad de Córdoba, 2009.

Crespo, Ana, “¿Redes de dependencia inter-imperial? Aproximaciones teóricas a la funcionalidad de los agentes de comercio en la expansión de las sociedades mercantiles", en Igor Pérez Tostado y Enrique García Hernán (eds.), Irlanda y el Atlántico Ibérico. Movilidad, participación e intercambio cultural, Valencia, Albatros Ediciones, 2010; 35-50.

Damonte, Mario, "La famiglia Serra e Gian Carlo Serra" en La Storia dei Genovesi, Atti del Convegno di Studi sui ceti dirigenti nella istituzioni della repubblica di Genova. Genova, 10-12 de giugno 1987, Génova, Centro internazionale di studi sui ceti dirigenti nelle istituzioni della Repubblica di Genova, 1988 (VIII): 243-271.

De Carlos Morales, Carlos, «Política y finanzas», en José Martínez Millán y Maria Antonietta Visceglia (eds.), La monarquía de Felipe III: la Corte, Madrid, Fundación Mapfre, 2008, (III): 749-867.

Domínguez Ortiz, Antonio, Política y Hacienda de Felipe IV, Madrid, Pegaso, D.L., 1960.

Doria, Giorgio, "Conoscenza del mercato e sistema informativo: il know-how dei mercanti-finanzieri genovesi nei secoli XVI e XVII" en Aldo De Maddalena y Hermann Kellenbenz (eds.), La repubblica internazionale del denaro tra XV e XVII secolo, Bolonia, Il Mulino, 1986; 57-122.

Elias, Norbert, La sociedad cortesana, México, Fondo de Cultura Económica, 1982.

Felloni, Giuseppe, "Il ceto dirigente a Genova nel sec. XVII: governanti o uomini d'affari?", en Giuseppe Felloni, Scritti di Storia Economica, Génova, Atti della Società Ligure di Storia Patria, 1999; 1323-1340.

García Montón, Alejandro, "Trayectorias individuales durante la quiebra del sistema hispano-genovés: Domingo Grillo (1617-1687)”, en Manuel Herrero Sánchez, Carlo Bitossi, Yasmina Rocío Ben Yessef Garfia y Dino Puncuh (eds.), Génova y la Monarquía, 1528-1713, Génova, Atti della Società Ligure di Storia Patria, Nuova Serie, LI (CXXV), fasc. I, 2011, (I): 367-384.

Gentil Da Silva, José, Stratégie des affaires à Lisbonne entre 1595 et 1607. Lettres des marchandes des Rodrigues d'Evora et Veiga, París, SEVPE, 1956. 
Greene, Peter, Negotiated Authorities: Essays in Colonial Political and Constitutional History, Charlottesville, University Press of Virginia, 1994.

Grendi, Edoardo, I Balbi. Una famiglia genovese fra Spagna e Impero, Turín, Einaudi, 1997.

Herrero Sánchez, Manuel, "Una república mercantil en la órbita de la Monarquía Católica (1528-1684). Hegemonía y decadencia del agregado hispano-genovés”, en Bruno Anatra y Francesco Manconi (dirs.), Sardegna, Spagna e Stati Italiani nell'età di Carlo V, Roma, Carocci, 2001;183-200.

Herrero Sánchez, Manuel, "La Monarquía Hispánica y las comunidades extranjeras. El espacio del comercio y del intercambio en Madrid y Cádiz en el siglo XVII", Torre de los Lujanes, 46 (Madrid, 2002): 97-116.

Herrero Sánchez, Manuel, "La quiebra del sistema hispano-genovés (1627-1700)", Hispania, LXV/1, 219 (Madrid, 2005): 115-152.

Herrero Sánchez, Manuel, "La red genovesa Spínola y el entramado transnacional de los marqueses de los Balbases al servicio de la Monarquía Hispánica”, en Bartolomé Yun Casalilla (dir.), Las redes del Imperio, Madrid, Marcial Pons, 2008; 97-134.

Herrero Sánchez, Manuel y Pérez Tostado, Igor, “Conectores del mundo atlántico: los irlandeses en la red comercial internacional de los Grillo y Lomelín”, en Igor Pérez Tostado y Enrique García Hernán (eds.), Irlanda y el Atlántico, Valencia, Albatros, 2010, págs. 307-321.

Herrero Sánchez, Manuel, Bitossi, Carlo, Ben Yessef Garfia, Yasmina Rocío y Puncuh, Dino (eds.), Génova y la Monarquía, 1528-1713, Génova, Atti della Società Ligure di Storia Patria, Nuova Serie, Vol. LI (CXXV), fasc. I, 2011, vols. 1 y 2.

Herrero Sánchez, Manuel y Álvarez-Ossorio Alvariño, Antonio, "La aristocracia genovesa al servicio de la Monarquía Católica: el caso del III marqués de Los Balbases (1630-1699)", en Manuel Herrero Sánchez, Carlo Bitossi, Carlo, Yasmina Rocío Ben Yessef Garfia y Dino Puncuh (eds.), Génova y la Monarquía, 1528-1713, Génova, Atti della Società Ligure di Storia Patria, Nuova Serie, Vol. LI (CXXV), fasc. I, 2011, vol. 1; 331-365.

Imízcoz Beunza, José María y Oliveri Korta, Oihane, Economía doméstica y redes sociales en el Antiguo Régimen, Madrid, Sílex, 2010.

Kirk, Thomas, Genoa and the Sea. Policy and Power in an Early Modern Maritime Republica, 1559-1684, Baltimore, Johns Hopkins University Press, 2005.

Lamberti, Maria Carla, "Mercanti tedeschi a Genova nel XVII secolo: l'attività della Compagnia Raynolt negli anni 1619-20”, Atti della Società Ligure di Storia Patria, XII/I (Liguria, 1972): 72-121.

Maréchaux, Benoît, "Cultiver l'alternative au système philo-hispanique: attraction, diffusion et appropriation du modèle vénitien dans la pensée républicaniste génoise du premier XVIIè siècle", en Manuel Herrero Sánchez, Yasmina Rocío Ben Yessef Garfia, Carlo Bitossi y Dino Puncuh (eds.), Génova y la Monarquía, 1528-1713, Génova, Atti della Società Ligure di Storia Patria, Nuova Serie, Vol. LI (CXXV), fasc. I, 2011, vol. II; 657-693. 
Maréchaux, Benoît, "Negociar, disuadir y comunicar para la conservación y reputación de la Monarquía: la república de Venecia en las estrategias de la Pax Hispánica bajo el valimiento de Lerma “, en Bernardo García García, Manuel Herrero Sánchez y Alain Hugon (dirs.), El arte de la prudencia. La Tregua de los Doce Años en la Europa de los Pacificadores, Madrid, Fundación Carlos de Amberes, 2012; 91-120.

Marsilio, Claudio, Lo Basso, Luca y Álvarez Nogal, Carlos, "La rete finanziaria della famiglia Spinola: Spagna, Genova e le fiere di cambio (1610-1656)", Quaderni Storici, 124/1 (Bologna, 2005): 97-110.

Martínez Millán, José y Visceglia, Maria Antonietta, La monarquia de Felipe III, Madrid, Fundación Mapfre, 2008/2009, 4 vols.

Muto, Giovanni, "La nobleza napolitana en el contexto de la Monarquía Hispánica: Algunos planteamientos", en Bartolomé Yun Casalilla (dir.), Las redes del Imperio. Elites sociales en la articulación de la Monarquía Hispánica, 1492-1714, Madrid, Marcial Pons, 2009; 135-171.

Neri, Enrica, Uomini d'affari e di governo tra Genova e Madrid (secoli XVI e XVII), Milán, Vita e Pensiero, 1989.

Pacini, Arturo, “Genova e Spagna”, en José Martínez Millán y María Antonietta Visceglia, La Monarquía de Felipe III: Los reinos, Madrid, Fundación Mapfre, 2008, vol. III; 1100-1133.

Podestà, Emilio, Musella, Silvana y Augurio, Francesco, I Serra, Turín, Testo\&Immagine, 1999.

Pulido Bueno, Ildefonso, El gran mercader y la corte real del Renacimiento. La familia genovesa Centurión (mercaderes, diplomáticos y hombres de armas), al servicio de España. 1380-1680, Huelva, Artes Gráficas Andaluzas, 2004.

Rubio, José Antonio, "La fundación del Banco de Ámsterdam (1609) y la banca de Sevilla", Moneda y crédito, 24 (Madrid, 1948): 3-31.

Sanz Ayán, Carmen, Los banqueros de Carlos II, Valladolid, Universidad de Valladolid, 1988.

Sanz Ayán, Carmen, «Octavio Centurión, I marqués de Monesterio. Un 'híbrido' necesario en la monarquía hispánica de Felipe III y Felipe IV», en Manuel Herrero Sánchez, Yasmina Rocío Ben Yessef Garfia, Carlo Bitossi y Dino Puncuh (eds.), Génova y la Monarquía, 1528-1713, Génova, Atti della Società Ligure di Storia Patria, Nuova Serie, Vol. LI (CXXV), fasc. I, 2011, vol. II; 847-872.

Tenenti, Alberto, Naufrages, corsaires et assurances maritimes a Venice, 1592-1609, París, SEVPEN, 1959.

Vitale, Vito, Diplomatici e consoli della Repubblica di Genova, Génova, Società Ligure di Storia Patria, 1934.

Recibido: $23 / 05 / 2011$

Aceptado: 14/07/2012 